\title{
Pemerataan Pembangunan Sosial Ekonomi antara Indonesia Timur - Barat sebagai Upaya Mempererat Kebhinekaan
}

\author{
Muhammad Rifa'at Adiakarti Farid \\ * Universitas Islam Negeri Sunan Kalijaga, Yogyakarta \\ rifaatfarid@gmail.com
}

\begin{tabular}{l}
\hline INFO ARTIKEL \\
\hline Riwayat Artikel: \\
Diterima: 12 Oktober 2018 \\
Disetujui: 25 Juni 2019 \\
\end{tabular}

Kata kunci:

Pemerataan Pembangunan

Desentralisasi

Kebhinekaan

\author{
Alamat Korespondensi: \\ Muhammad Rifa'at Adiakarti Farid, \\ Islam Pembangunan dan Kebijakan Publik \\ Universitas Islam Negeri Sunan Kalijaga, Yogyakarta \\ Email: rifaatfarid@gmail.com

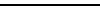

\begin{abstract}
This article will examine the problem of regional disparity in Indonesia, which has been the problem of decentralization increasingly complex with high levels of poverty in the regions. At the end of this paper will also be discussed about the equitable distribution of economic and social development related to the impact of national security and diversity issues. If the problem of inequality continues to be left, the worst impact will be the release of regions that are actually resource-rich but there is no even development. .

Abstrak: Artikel ini akan mengkaji masalah kesenjangan wilayah di Indonesia yang selama ini, masalah desentralisasi semakin kompleks dengan tingginya tingkat kemiskinan di daerah. Di akhir tulisan ini juga akan dibahas mengenai pemerataan pembangunan ekonomi dan sosial terkait dampaknya dengan ketahanan bangsa dan masalah kebhinekaan. Jika masalah kesenjangan terus dibiarkan, maka dampak terburuk akan lepasnya daerah yang sebenarnya kaya sumberdaya tetapi tidak terjadi pembangunan secara merata.
\end{abstract} ABSTRAK

\section{LATAR BELAKANG}

Dalam kehidupan berbangsa, bernegara dan bermasyarakat Indonesia berpegang teguh pada ideologi Pancasila. Pancasila telah diterima sebagai satu- satunya azas dalam kehidupan berbangsa, bernegara, dan bermasyarakat. Namun demikian, implementasi jiwa dan semangat yang terkandung dalam Pancasila tidak sepenuhnya diamalkan, bahkan dewasa ini penyimpangan terhadap sila kemanusiaan yang adil dan beradab serta keadilan sosial bagi seluruh rakyat Indonesia seolah-olah semakin menjauh dari bangsa ini. Dan ini merupakan kelemahan yang patut untuk diminimalisasi, sehingga cita-cita pendiri bangsa agar Pancasila menjadi pandangan hidup bangsa Indonesia benar-benar dapat diimplementasikan secara utuh dan menyeluruh dalam segala lini.

Kekuatan ekonomi nasional saat ini ditopang oleh sektor primer dan sekunder. Keberadaan sumber kekayaan alam yang demikian besar telah memberikan kekuatan ekonomi berbasis sumberdaya alam dan lingkungan. Namun demikian, kekuatan ekonomi seperti ini perlu diiringi dengan pengembangan sistem perekonomian berbasis nilai tambah (added value), sehingga dibutuhkan sistem perindustrian yang lebih baik. Selain itu, praktek perekonomian biaya tinggi (high cost economy) masih kerap berlaku di Indonesia, sehingga dapat menghambat pembangunan nasional. Kekuatan bangsa Indonesia dalam konteks sosial-budaya adalah terletak pada kebhinekaannya. Bhineka Tunggal Ika sebagai motto negara telah menjadi dasar pandangan kehidupan berbangsa dan bermasyarakat bahwa Indonesia adalah sebuah Negara Kesatuan yang berbentuk Republik. Artinya bahwa warna dan ragam suku merupakan khasanah kehidupan, tetapi jiwa dan semangatnya tetap satu, yaitu berbangsa satu bangsa Indonesia, berbahasa satu bahasa Indonesia dan bertanah air satu tanah air Indonesia. Namun demikian, ketika kebhinekaan tersebut tidak dapat dibina dengan baik, maka bukan tidak mungkin NKRI akan teramcam keberadaannya. 
Selama 70 tahun ada beberapa masalah yang dihadapi Indonesia. Antara lain kemiskinan wilayah, kesenjangan daerah Indonesia Barat - Indonesia Timur. Jika hal ini tidak dapat diatasi dengan baik, maka dikhawatirkan akan menggangu kondisi negara Indonesia. Karena pada umumnya, pembangunan sosial ekonomi Indonesia banyak terpusat di bagian Indonesia Barat, wilayah Indonesia Timur cenderung belum berkembang. Wilayah Indonesia Timur pada dasarnya kaya akan sumber daya alam, yang selama ini belum dapat dieksploitasi dengan baik guna kemakmuran bersama. Ataupun sudah dieksploitasi tetapi hanya untuk kepentingan Indonesia Barat atau konsesi sumbar daya banyak dialokasikan untuk kepentingan negara/pemerintah pusat

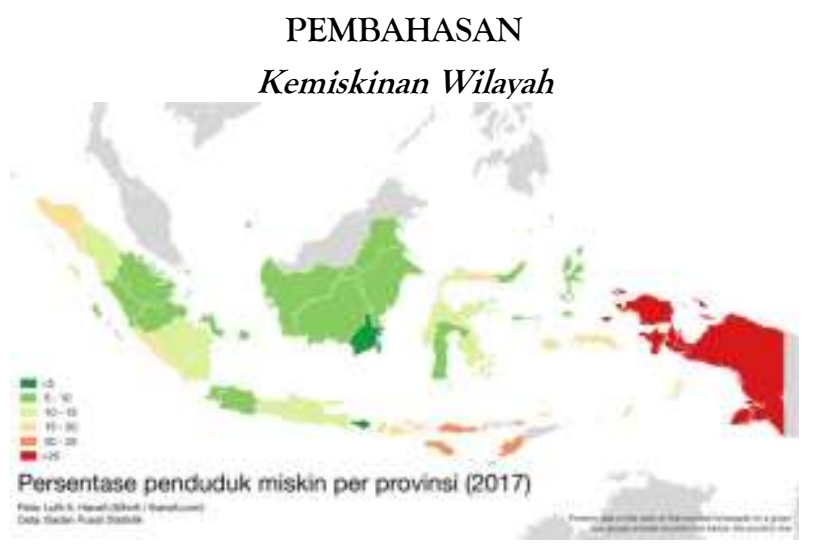

Gambar 1. Peta Persentase Penduduk Miskin per Provinsi Tahun 2017

Kemiskinan masih menjadi permasalahan utama Indonesia sejak beberapa dekade yang lalu. Jika dikaitkan dengan kawasan Indonesia Timur, masalah kemiskinan erat kaitannya dengan kesenjangan sosial ekonomi wilayah. Jika hal ini dikaitkan dengan isu keadilan dalam pembangunan kewilayahan akan selalu menjadi perbincangan hangat yang tidak selesai diperdebatkan, terutama terkait dengan masalah kesenjangan wilayah (regional imbalances). Sampai saat ini isu kesenjangan wilayah terpusat kepada kesenjangan antara desa dan kota, antara Kawasan Indonesia Timur dan Kawasan Indonesia Barat, serta antara Jawa dan luar Jawa. Banyak pakar yang percaya bahwa kesenjangan wilayah merupakan harga wajar yang harus dibayar dalam proses pembangunan. Sederhana saja alasannya, yakni ada keterkaitan antara wilayah satu dengan wilayah yang lain sebagai akibat buruknya sebuah sistem pembangunan regional yang dianut Indonesia.

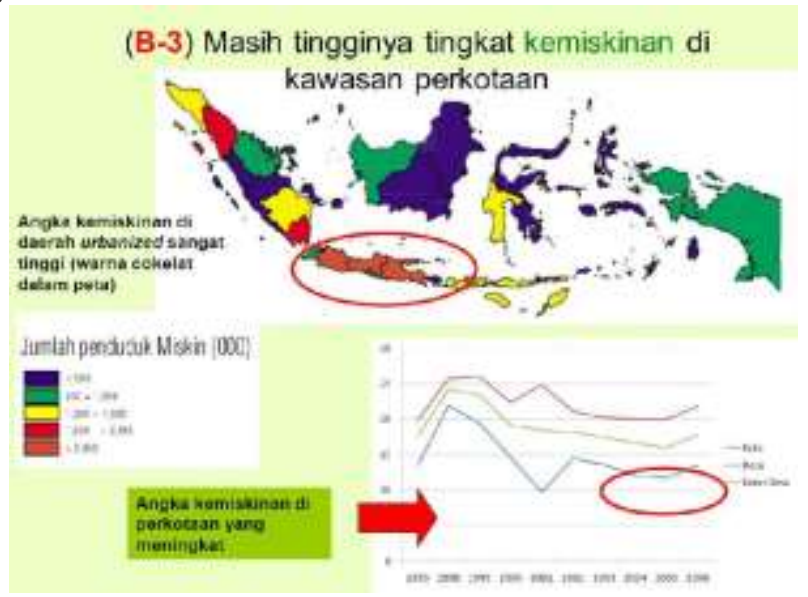

Gambar 2. Peningkatan Angka Kemiskinan di Perkotaan

Ada proses interaksi dan interdependensi antar subsistem. Indikator yang digunakan untuk memperlihatkan bahwa sebuah wilayah dianggap lebih maju dibandingkan dengan wilayah yang lainnya cukup banyak. Hill (1993) misalnya menyebut indikator yang bersifat statis seperti Indeks Pembangunan Manusia (human development index), Indeks Kualitas Kehidupan secara Fisik (physical quality of life index), maupun laju PDRB (product domestic regional bruto). Data seperti ini meskipun tidak secara mutlak dapat dipercaya begitu saja, namun dapat digunakan sebagai gambaran awal betapa sebuah wilayah da[at lebih maju dibanding wilayah yang lain. Sebagai contoh Jakarta yang memiliki PDRB per kapita sebesar 1,76 juta rupiah pada tahun 1991, jauh lebih tinggi dibanding rata-rata PDRB per kapita secara nasional yang hanya 0,55 juta rupiah pada tahun yang sama. 


\section{Kesenjangan Sosial Ekonomi Indonesia Barat - Indonesia Timur}

Gambaran sederhana ini hanya ingin menunjukkan bahwa Jakarta berkembang terlalu pesat dibandingkan dengan wilayah lainnya antara lain ditandai dengan jumlah uang yang beredar di Jakarta mencapai $70 \%$ dari peredaran uang nasional. Fakta ini juga menunjukkan bahwa pembangunan sebuah wilayah dipengaruhi oleh sebuah faktor penting, yakni investasi pembangunan daerah, sedangkan kesenjangan wilayah terjadi jika alokasi investasi antardaerah juga timpang (Aziz,1985). Kesenjangan ini tidak hanya terjadi dalam bidang ekonomi, tetapi dalam bidang sosial juga. Indikator yang digunakan dalam bidang ekonomi adalah : 1). Jumlah pendapatan per kapita; 2). Pertumbuhan pendapatan per kapita; 3). Tingkat partisipasi angkatan kerja; 4). Persentase nilai tambah sektor manufaktur terhadap PDRB total provinsi; 5). Persentase tenaga kerja yang bekerja di sektor manufaktur dibandingkan tenaga kerja total provinsi; 6). Tingkat penanaman modal asing dan dalam negeri secara kumulatif; 7). Persentase penduduk yang tinggal di perkotaan; dan 8). Panjang jalan/10.000 km persegi luas provinsi.

Pada bidang sosial, kesenjangan ditunjukkan oleh fakta dengan indikator seperti : 1). Physical Quality of Life Index; 2). Jumlah murid sekolah dasar dibanding jumlah total penduduk; 3). Persentase tenaga keja yang berpendidikan akademi atau universitas; 4). Rasio guru sekolah dasar tiap 10.000 murid; 5). Rasio dokter setiap 10.000 penduduk; dan 6). Rasio tempat tidur sakit tiap 10.000 penduduk. Berdasarkan indikator-indikator tersebut, memang benar ditemukan adanya kesenjangan wilayah yang cukup besar antara kawasan Indonesia Barat (KIB) dan kawasan Indonesia Timur (KIT), yakni indeks rata-rata KIB dan KIT masing-masing 108,2-81,5 (1971), 110,7-75,9 (1980), dan 112,972,2 pada tahun 1990 (Nurzaman,1997).

Namun, jika dirinci setiap sektor ekonomi, maka sumber daya alam seperti gas, minyak dan pertambangan memberikan kontribusi besar di beberapa provinsi antara lain di Sumatera Selatan (minyak dan batubara), Papua (tembaga dan emas), Sulawesi (nikel). Sedangkan sektor jasa keuangan seperti bank, industri pengolahan sumberdaya alam, bangunan, konstruksi, pengangkutan, komunikasi, dan sebagainya, hanya terkonsentrasi di provinsi maju seperti DKI Jakarta atau provinsi yang lain di pulau Jawa. Hal ini dapat dicermati dalam distribusi persentase PDRB Jakarta sekitar 16,06 \% pada tahun 2007 dan pada tahun yang sama NTT, NTB, Papua Barat dan Papua masing-masing hanya 0,54\%, 0,95\%, 0,29\%, dan 1,57\% (BPS,2008).

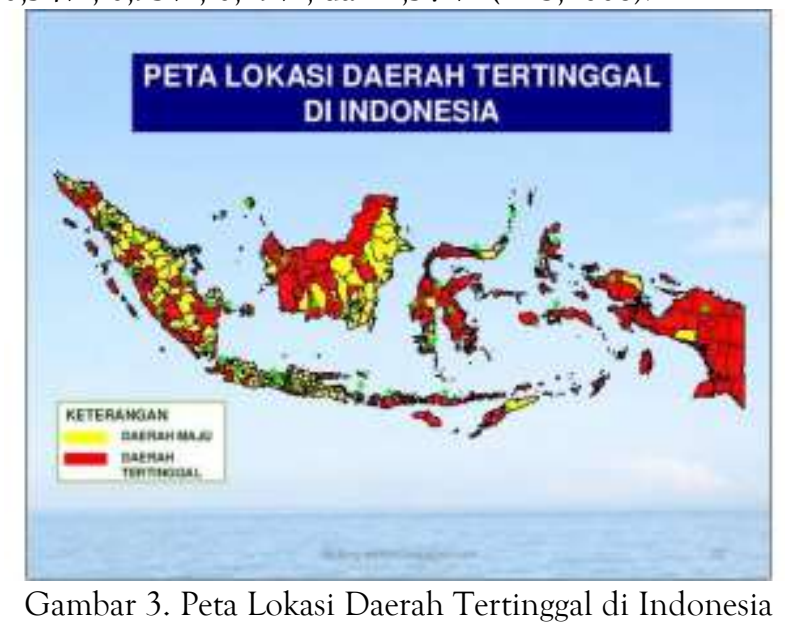

Selama ini desentralisasi pembangunan hanya untuk konteks daerah tertentu seperti daerah tertinggal terbelakang atau daerah dengan potensi strategis seringkali tidak disertai strategi yang tepat dan bernuasa politis, terutama jika berkaitan dengan isu keuangan.

\section{Pengembangan Wilayah Kawasan Khusus}

Pengembangan wilayah yang dilaksanakan di Indonesia setidaknya meliputi tiga tingkatan, yakni mikro, mezo, dan makro. Pada tingkat mikro bertujuan untuk mengenali kebutuhan yang mendesak dan memenuhi kebutuhan dasar masyarakat, membantu daerah dalam rangka mencapai kemandirian ekonomi, meningkatkan daya saing, serta mendorong pengembangan potensi daerah agar mampu mengekspor hasil industri atau pertaniannya untuk mendukung perekonomian nasional (Soedjito, 1997). Pada tingkat mezo dilakukan pengembangan wilayah dengan jalan mengaitkan antar-wilayah agar tercipta pusat-pusat pertumbuhan. Kawasan yang menjadi prioritas diantaranya : kawasan cepat tumbuh, kawasan perbatasan, kawasan potensial. Banyak istilah yang dilontarkan untuk menandai strategi ini, misalnya : kawasan pembangunan ekonomi terpadu (Kapet), Kawasan Sijori, atau Kawasan perkotaan seperti Jabodetabek (Jakarta,Bogor, Depok, Tangerang, Bekasi), Bandung Raya, Kedungsepur (Semarang, Demak, Ungaran, Purwodadi), Gerbangkertasusilo (Gresik, Bangkalan, Mojokerto, Surabaya, Lamongan, Sidoarjo), Joglosemar (Jogja, Solo, Semarang), dan sebagainya. Terlepas dari apapun namanya, upaya yang hendak dilakukan adalah untuk mengaitkan antar wilayah (kota) agar tercipta pusat-pusat pertumbuhan. Masalah yang sering muncul, sebutan kawasan-kawasan tersebut hanya berhenti sebagai 
slogan, tanpa visi misi yang jelas. Apalagi kini desentralisasi telah menempatkan kepala daerah atau walikota memiliki kekuasaan yang mutlak serta absolut, maka yang terjadi selanjutnya adalah egoisme antar daerah. Antara daerah yang satu dan daerah yang lain, sama-sama mempunyai kepentingan terhadap daerahnya sendiri.

Dalam hal otonomi daerah, ada 4 aspek yang menjadi kewenangan daerah yaitu agama, pertahanan, keuangan dan hukum. Yang berkaitan dengan keuangan seperti pembangunan antar wilayah seperti konflik antara Boyolali dan Surakarta yang memperebutkan penggunan sumber daya air. Boyolali dalam satu sisi ingin Kota Surakarta memberikan bantuan untuk konservasi sumber daya air, karena dua wilayah menggunakan air dari tempat yang sama.

\section{SIMPULAN DAN SARAN}

\section{Simpulan}

Sebagaimana telah dikatakan pada awal tulisan ini, kesenjangan wilayah merupakan hal yang wajar dalam sebuah pembangunan. Masalah pokok yang harus dipecahkan adalah adanya konsepsi kuat untuk jangka waktu yang panjang yang dilandasi keadilan sosial, serta adanya sistem ekonomi politik negara yang tidak memihak terlalu kuat pada wilayah tertentu. Jalan yang harus ditempuh diantaranya bagaimana memberi kemandirian sekaligus dukungan kepada sebuah wilayah sehinga mereka memiliki daya saing. Daerah-daerah yang kurang berkembang didorong dengan mobilisasi seluruh kelembagaan, baik dari kalangan perguruan tinggi, LSM, dunia penelitian, pengusaha kecil menengah dan pengusaha besar, lembaga keuangan daerah, lembaga keuangan nasional, serta kemampuan aparatur daerah yang terampil dan memiliki visi misi ke depan yang jelas. Membangun keutuhan Negara Kesatuan Republik Indonesia tidak bisa dilakukan secara parsial melainkan membutuhkan peran segenap komponen bangsa. Peran tersebut harus dimulai sejak dini dengan memberikan dasar-dasar dan pandangan hidup universal. Nilai universal dalam kehidupan berbangsa, bernegara dan bermasyarakat terdapat dalam Pancasila sebagai dasar dan falsafah bangsa Indonesia.

Pembangunan wilayah Indonesia masih timpang antara Indonesia Barat - Indonesia Timur, hal ini akan menimbulkan kecemburuan sosial di antara dua wilayah tersebut. Jika dibiarkan secara terus menerus maka masalah disintegrasi bangsa akan semakin kelihatan. Dimana wilayah yang kaya dengan sumber daya akan bergejolak/menuntut penyebaran kesejahteraan secara merata. Jika hal ini tidak diselesaikan dengan baik dan benar, maka masalah disintegrasi bangsa akan berujung kepada tindakan separatisme. Tindakan memisahkan diri dari NKRI akan menjadi pilihan terpaksa yang bisa saja ditempuh. Seperti pada Papua yang memperebutkan sumber daya emas, tembaga yang selama ini dikuasasi oleh Freeport, pihak Papua sendiri hanya mendapatkan konsesi tak lebih dari 5\%. Dalam teori ketidakseimbangan pertumbuhan wilayah, dinyatakan bahwa kekuatan pasar sendiri tidak dapat menghilangkan perbedaan-perbedaan antarwilayah dalam satu negara, bahkan sebaliknya kekuatankekuatan ini cenderung akan menciptakan dan boleh jadi malahan memperburuk keadaan. Kemiskinan di negara berkembang merupakan hasil kerja dari produktivitas tenaga kerja yang rendah yang merupakan bagian dari ketidakcukupan penawaran dan modal-modal fisik. Demikian pula tabungan juga rendah karena pendapatan rendah. Karenanya keseimbangan pertumbuhan dapat diciptakan jika investasi dapat didiversifikasikan ke rentang yang lebih luas di sektor industri. Masing- masing industri akan didorong oleh faktor upah, permintaan barang, dan kecukupan industri yang lain untuk menjaga keberlangsungan kehidupannya. Proyek-proyek investasi mungkin secara individual tidakmenguntungkan bisa berbalik menjadi menguntungkan.

\section{Saran}

Strategi pembangunan harus dipusatkan kepada sedikit sektor lalu disebarkan "backward linkage" dan "forward linkage". Jika leading sector dikaitkan dan disebarkan ke berikutnya, dari perusahaan satu ke perusahaan yang lain. Namun yang jelas, kurangnya keterkaitan ke belakang atau backward linkage banyak disebabkan oleh lemahnya permodalan petani di negara berkembang. Pada umumnya para petani sangat tergantung produkproduk pertanian dari luar seperti obatobatan dan pupuk. Akibatnya mereka sering menjadi obyek permainan pasar. Jika panen berlimpah harga turun drastis, jika musim tanam tiba pupuk dan obat- obatan menghilang.

\section{DAFTAR RUJUKAN}

Aziz, I. J. (1985). Pembangunan Daerah dan Aspek Alokasi Investasi Antardaerah. Prisma, (6), 3-21.

Hill, H. (1990). Indonesia's industrial transformation part I. Bulletin of Indonesian Economic Studies, 26(2), 79-120.

Kaelan., Zubaidi, A. (2007). Pendidikan Kewarganegaraan. Yogyakarta: PARADIGMA. 
10 Instructional Development Journal (IDJ), Vol. 2, No. 1, Juni 2019, Hal. 6-10

Mahifal. (2011). Membangun Keutuhan Negara Kesatuan Republik Indonesia melalui Pembinaan Ideologi dan Wawasan Kebangsaan, Jurnal Pedagogia.

Wilonoyudho, S. (2009). Kesenjangan dalam pembangunan kewilayahan. In Forum Geografi (23), 2, pp. $167-180$.

Soedjito, B. B. (1997). Strategi Pengembangan Kawasan Timur Indonesia” dalam Bunga Rampai Perencanaan Pembangunan di Indonesia. 